\title{
Examination of Urban Agriculture Contribution to the Household Livelihood Outcome the Case of Bahir Dar City, Ethiopia
}

\author{
Desalegn Degu Tebeje ${ }^{1}$, Sitota Getachew Bokore ${ }^{2}$ \\ ${ }^{1}$ Department of Economics, Injibara University, Injibara, Ethiopia \\ ${ }^{2}$ Department of Accounting and Finance, Injibara University, Injibara, Ethiopia \\ Email address: \\ enatdegu1445@gmail.com (D. D. Tebeje), kenagetch@gmail.com (S. G. Bokore)
}

To cite this article:

Desalegn Degu Tebeje, Sitota Getachew Bokore. Examination of Urban Agriculture Contribution to the Household Livelihood Outcome the Case of Bahir Dar City, Ethiopia. Journal of World Economic Research. Vol. 9, No. 2, 2020, pp. 133-141. doi: 10.11648/j.jwer.20200902.18

Received: December 10, 2019; Accepted: October 14, 2020; Published: December 16, 2020

\begin{abstract}
The general objective of this study is to examine the contribution of urban agriculture to the household livelihood in case of Bahir Dar city in Ethiopia. The motive for this study were the problems of unemployment, growing poverty, hunger, poor diets, bad air condition, depression as well as the special opportunities provided by the city including the growing demand for food, proximity to markets and availability of cheap resources such as urban organic wastes. The study used both primary and secondary data source. Stratified quota sampling was used by the study to collect primary data. Average annual urban agricultural net revenue per capita was taken as a common measure of all urban agricultural outcomes for target predictor's. Other predictor variables that assumed to be the determinant of urban agriculture contribution also included in the model. Binary logistic regression technique is used to estimate the logit coefficient. The studies found that the greater correlation of livelihood security's with average annual urban agricultural net revenue per capita than average annual non- urban agricultural net revenue per capita. The correlation between food, economic, education, health and empowerment security with average annual urban agricultural net revenue per capita were about $0.29,0.6,0.19,0.21$ and 0.22 respectively. This target explanatory variable was positive significant effect for food security dependent variable at $5 \%$ significance level and at its mean value the probability of more food security agreement were about 0.77 , while other predictors also held at their mean value. Finally, this studies paper suggests that urban agriculture helps for household livelihood outcome of food, education, health, empowerment and economic security and should be considered in urban planning.
\end{abstract}

Keywords: Urban Agriculture, Livelihood Securities, Agreement Level

\section{Introduction}

Urban agriculture is a practice of rural agriculture in urban context or it is primary occupation practiced within integrated urban socio-economic and ecological system and it used as a strategy by many urban dwellers to improve their livelihood and overall well-being [18].

By the year 2050 it is expected that 66.4 percent of the world's population will be living in cities [15]. So, for these growth of population [23] advice is necessary for urban households to embark on urban farming as a means of filling the food demand. Income and financial, technical, and educational support is essential to maximize the benefits of urban agriculture [18].
In developing countries urban agriculture one of several food security options for households livelihood security; similarly, it is one of several tools for making productive use of urban open spaces, treating urban waste, saving, generating income and employment, and managing freshwater resources more effectively [2] and it practiced anywhere between about $10-70 \%$ of urban households in third world countries [1].

The study helped to assess the contribution of UA to the livelihood of agricultural participant households and to show UA contribution to livelihood of urban households who practiced agriculture either allied with other job or as a major job to urban planner and other researchers.

Lack of formal employment opportunities, growing 
poverty, hunger, poor diets, physical inactivity, air pollution, depression, anxiety and financial insecurity as well as the special opportunities provided by the city including the growing demand for food, proximity to markets and availability of cheap resources such as urban organic wastes were the motive of this study [6] cited in [11]. Population growth and urbanization also the challenge in the world cities. In 2050 more than two-thirds of world population estimated to be living in urban areas and this could lead to a net addition of 2.4 billion people to towns and cities, which is more than the total global population increment of 2.2 billion, people worldwide [7].

In Ethiopia, 19.4\% peoples lived in urban areas in 2015 and between 2007 and 2015 nineteen million people were added to the population and population size was growing by 2.9 percent per year and it was expected to nearly double in less than 33 years to around 185 million in 2050 [20, 4]. In Bahir Dar city the total population was estimated to be 219,535 in 2015 [10]. In addition to that problem, some household livelihood depends on urban agriculture, although untreated wastes affect urban farmers, and upgrading methods or new technologies for farmers input is at its subsistence level $[3,8]$.

For the above problems the integration of urban agriculture into the cities and towns is a remedy that increases vegetation within the city, improving air quality and reducing the probability of urban populations suffering diseases worldwide [15]. That means household living with in good air quality and a healthy life with a capability of having enough household assets and the household members becomes strong and successful in undertaking livelihood strategies (activities) to get improved livelihood outcome.

Many theoretical literatures had existed related to this study. The most available theoretical literature related to title of this study written by [25] was about urban agriculture impacts on social, health, and economic. Even if it does not differentiate urban agricultural impacts specifically weather to the community or to the household, it was important literature for this study to know the contribution of urban agriculture.

The most related and recent existing empirical literature were urban agriculture, poverty and food security by [1] in developing countries; using nationally representative households data and they found that existence of positive association between urban agriculture and dietary adequacy and diversity. The second paper was contribution of urban agriculture to employment, income and food security in Kisumu municipality in Kenya by [19]. His study concludes that urban agriculture supplements food requirements of the urban poor on one hand and a source of income for the few commercial urban agricultural participant on the other hand. The third paper is urban agriculture a way of forwarding food and nutrition security in Malaysia by [24] and they suggest that more likely probability of improving food security by practicing urban agriculture. The fourth paper was contribution of urban agriculture to household's livelihoods in Roysambu ward in Nairobi by [10]. He suggested practicing urban agriculture not serves as major income sources but rather it supplements family incomes. The fifth paper was contribution of urban agriculture to household food security in Ibadan Metropolis in Nigeria by [21] and they conclude that urban agriculture was profitable. The sixth paper is urban agriculture and its effect on poverty alleviation in Ibadan Metropolis in Nigeria by [23]; they concluded that vegetable enterprise was profitable and could help to reduce poverty to a minimum level.

In the study area there was a little previous study slightly related to the title of the contribution of urban agriculture to the livelihood of urban farmer. Such study paper was about urban and peri-urban farming systems and utilization of the natural resources in Bahir Dar city and Dangla town, in Ethiopia written by [13]. They said that crop-livestock integration plays a vital role in the small holder farming systems and about $33.3 \%$ of the respondents practiced croplivestock farming.

All of the above empirical literature shows the contribution of urban agriculture to particular household livelihood security categories. But, this study paper different from above empirical papers in that the use of five broad livelihood security categories of [17] which was broader than simply taking of one livelihood security categories of a household. In addition to that this study paper try's to reconcile the two opposing views: that is some of those study papers implies UA supplements other livelihood strategies and not as a major livelihood activities and some other paper says UA serves as a major livelihood activities and it is profitable.

This study paper fill these gaps by examining the contribution of UA to the five broad livelihood security categories (food, health, education, empowerment and economic) in Bahir Dar city and its surroundings to the office of urban agriculture and also to the city planners as a solution of the above mentioned problems

The study is tries to answer the following question:

1. What are the determinants of UA contribution to food security status of agricultural participant households in Bahir Dar city?

2. Does urban agricultural revenue has a greater association with higher livelihood security than nonagricultural revenue in Bahir Dar city?

3. Does UA have contribution for minimizing food insecurity in Bahir Dar city?

The general objective is to examine the contribution of urban agriculture to the household livelihood outcome security in Bahir Dar city, Ethiopia. The following three specific objective were aimed to do.

1) To show the association UA contribution with livelihood security status of agricultural participant households in BDC.

2) To examine the contribution of UA to food security status of agricultural participant households in BDC.

3) To estimate the probability of more agreed food security households in respect to change UA revenue in BDC.

The study will have important to understand the current 
situation of urban agriculture. It gives emphasis for private and institutional researchers to allocate more resources in developing and promoting urban agriculture and it serve as reference for other studies interested on the related issues.

Due to time, financial and other constraints the study was geographically limited to Bahir Dar city administration area. The area was selected because of agricultural potential it has and the researcher's familiarity to the study area. It also conceptually limited to only the contribution of UA to the five broad livelihood security categories of household's [17].

The study paper has the following major limitations. One is perception measure of dependent variable was not good as of quantitative measurement, another limitation of the study was the interviewed households did not remember the needed correct information. Specially, agricultural sourced revenue and costs. Self-production for their consumption and to further agricultural production was the challenge for evaluation. To overcome these challenge study had used the average of the maximum (at most) and the minimum (at least) estimation of household head about their financial needed data. Another limitation of the study was the title broadness. This issue leads only food security studied by both descriptive and model alnyisis. The rest four (i.e. empowerment, health, education and economic) livelihood security categories of [17] studied using descriptive alnyisis. Generally, the study solution for the encountered challenges made the study to be valuable and important.

\section{Methodology of the Study}

\subsection{The Study Area}

The study was conducted at Bahir Dar city administration area which is capital of Amhara regional state since 1991 and situated at $566 \mathrm{~km}$ northwest of Addis Ababa which is capital city of Ethiopia [13].

Bahir Dar lies on a very gentle slope with elevation ranging between 1783 and 1889 meter above sea level and it occupies the head stream of the Blue Nile basin and the city covers a total area of $256.4 \mathrm{~km}^{2}$ [13]. The city administration area organized into 6 sub cities and 11 pre urban kebeles.

\subsection{Type of Data}

The study used both primarily and secondary data sources. The primarily data were discrete type for each indicator of the five [17] broad livelihood security categories that had made dependent variable except economic security. Why the study used discrete data type was the difficulty of livelihood security to get quantitative measurement. It was hard to collect quantitative data type since it needs large fund and longer time. In addition to that problem, the most of variable by nature was qualitative type (eg. empowerment). Therefore, discrete type of data were appropriate for the study for except economic security livelihood outcome with the constraint of a given resources. For economic security it was relatively easy to collect quantitative data type, so the study used continuous form for this variable. The independent variable data type was both dummy and continuous form.

\subsection{Measurement Type and Variable Definition}

The five [17] livelihood security categories has many indicators which was measured by five-point Likhert type ordinal scale level of agreement except economic security i.e. strongly disagree, disagree, neither agree nor disagree, agree, strongly agree [29] and their respective valuation is 1, 2, 3, 4, and, 5. Similarly, the same evaluation for economic security for very lower, lower, medium, higher and very higher by classifying economics security index into five.

In the side of dependent variable food security indicators are based on [8] experience questions. These questions of experiences measure are: you were not worried, you would not run out of food, you ate only many kinds of foods, your family did not skip a meal, your family ate not less than you thought you should, your family not ran out of food, your family were not hungry but did not eat and went without eating for a whole day.

For health security indicators also the study used perception question identified by [27] also used by [24]. Such questions were your family ate healthy and nutritious food over last year, your family never seek stomach pen, your family were happy over last year and your family were physically strong.

For empowerment: [24] identified and had used three indicators such as community participation, access to services and participation in the planning process. But, the study aimed to know the contribution of urban agriculture to empowerment of urban farmer's particularly. All household members participation in decision and specially females decision making for agricultural work was important indicator variable.

For empowerment: [24] identified and had used three indicators such as community participation, access to services and participation in the planning process. But, the study aimed to know the contribution of urban agriculture to empowerment of urban farmer's particularly. All household members participation in decision and specially females decision making for agricultural work was important indicator variable.

For education security: it is clear that agricultural income spent on one part of household requirement is on education [22] and agriculture as a teaching resource and natural laboratory [9]. To bring a connection between urban agriculture and education security, it had better to use experience based question such that agricultural revenue enables your family to learn in school and agriculture is a natural teaching material for your family over last year. For economic security: the study not used perception measure like as the previous measure of dependent variable. Economic security means access to adequate means of securing households livelihood outcomes [27]. In turn household's economic security represented by on their expenditures, which comes from household income, credit and saving level of households and household's physical 
asset. But, to construct economic security index, that was enough to used Credit, saving and annual household revenue. Because, a household physical asset level directly or indirectly related with these selected variable. The construction of the indexes was the same as the previous index construction in the subsequent formula of 1 and 2 and then by 3 .

The credit level valued from one to five in such a way that higher debited households with lower value and lower debited households associated with higher value. For household annual net revenue and saving level of household also valuated one up to five but in reverse way of debit level of households. Finally, the study had constructed comprehensive index and then classified in to two. Each of indicators was constructed sub- index using formula of:

$$
\text { Zindij }=\left(\text { indicator }_{\mathrm{ji}}-\min _{\mathrm{j}}\right) /\left(\max _{\mathrm{j}}-\min _{\mathrm{j}}\right)
$$

Where ' $j$ ' is indicator variable and 'zind' is the index for each household ' $i$ '. This formula was important to construct five broad livelihood security categories [17]. The minimum and maximum values of the indicators are one and five respectively accept economic security indicator. After that, it was better to determine the index for each five broad [17] livelihood security categories using the following formula.

$$
\begin{gathered}
\text { SI mi }=\frac{\sum_{j=1}^{n} Z_{i n d_{i j}}}{L} \\
Y_{m i}=\frac{S I_{m i}}{2}
\end{gathered}
$$

Note: if the value of Ymi equals to 0.5 or greater, household are more agreed on specific livehood security, otherwise lower agreed.

Where ' $L$ ' number of indicator, 'SImi' is any of fivesecurity index of household ' $i$ ' and ' $\mathrm{m}$ ' is a subscript to show economic, education, health and empowerment security. 'Ymi' also the level of agreement of livelihood security (it can be lower or higher). Hence after constructed the index for each, it had been used five point broad (compressive) level of agreement for each livelihood security whether urban agricultural participant households in Bahir Dar city more agreed or not (lower agreed) in their securement of food, education, health, empowerment and for economic security wither households relatively higher secured or not (lower) as showed in the above equation one and two.

The following were explanatory variables for both descriptive and food security model alnyisis.

1) Average annual urban agricultural net revenue per capita $(H)$ : This variable was the main target variable and the variable data were collected systematically. Because, households they did not remember the exact revenue gained and costs incurred especially for their agricultural livelihood activities. By nature, agriculture work might be needed relatively longer time than other livelihood activities to get what they need at the end (revenue) and urban agricultural revenue basically used for self-consumption, for cash sale and it maybe also used for others like further agricultural production. Therefore, for the solution of above challenge's, average of households head estimation about his family UA revenue at most and at least over last year was taken in all the case of allocation of revenue for the separate group source of agricultural revenue such that fruit \& vegetable, grain and teef, animal fattening, fishing, bee keeping, cattle rearing, sheep, goats, hen rearing and Other UA source of revenue livelihood choice.

Then, summed the whole average annual UA revenue of different sources and then deducted the average annual UA cost (it was collected with the same method of collecting average revenue for all possible input cash cost and non-cash cost) divided by family size.

2) Average of net-annual non-agricultural income per capita $(K)$ : This variable also one of the determinant of household livelihood security. For this variables the study was used the same method of collecting and preparing data with the average annual urban agricultural net revenue per capita, except it was collected for monthly and then changed to year (multiply by 12).

3) Dependency ratio ( $D R)$ : It is the ratio of non-working individuals to working individuals and it is negatively associated with household wellbeing [28]. That is the higher dependency ratio related with lower household wellbeing. So, it can be the predictor's of household livelihood security.

3) Average education level (AEL): It is one of a human capital proxy and it linked with a higher probability of a household well-being [28] and he suggests that wellbeing tends to increase with average educational level. Its measurement type was ratio i.e. the total sum of each education year of literate individual's household member divided by total number of family. This variable is not an explanatory for education security dependent variable.

4) Residential land size (RLSPC): It affects urban household livelihood positively [28]. To minimize the effect of family size, its value was divided by family size to change into per capita form.

5) Farm land size per capita (FLSPC): Urban agricultural households dependent on farm land size. The higher farm land size associated with higher urban agricultural income [5, $23,28,21]$. Its value was divided by family size to change in to per capita form.

6) Location dummies (LOCDUM): Urban agriculture more practiced in the prei- urban area than urban area and the location of household's resident determined the livelihood of HHs [5].

\subsection{Data Source}

Although most of the variable data were primary, the secondary data from the office of Bahir Dar city Urban Agriculture, Land and Environment Protection Authority used to get the total population of urban agricultural participants. The primary data was collected from household agricultural participants in collaboration with each kebeles urban agriculture office. 


\subsection{Sampling Technique}

Stratified quota samplings were used in the study. Quota sampling has used to get sample size in each stratum of 11 pre-urban kebeles and six-sub cities. Using quota sampling the sample size had selected proportionally in each stratum and given quotas to be selected in each. Also, no need of list of population in this sampling and the study only needed the size of population. The study had used quota sampling to overcome basically two challenges encountered though the field works. One is most of households were irresponsive for giving the true information, so quota sampling enabled to substitute by another responsive households on the same stratum. The second challenge was time resources was scarce to collect the data and unavailability of research fund. Therefore, the study used stratified quota sampling in order to overcome these challenges.

\subsection{Sample Size Determination}

In Bahir Dar city administration area 12241 peoples participated in urban agriculture [3]. From 399 urban agricultural households, the data were collected from 17 stratum proportionally using the formula of $n *$ pi. Where pi were proportion of targeted population included in stratum i and $n$ were total number of urban agricultural participants.

\subsection{Method of Data Collection}

The data were collected through structured and nonstructured questioner. Except for non-urban agricultural revenue and costs, the data was collected yearly information. For other than urban agricultural revenue and cost date were collected monthly information and then take yearly estimation. Households they did not remember their revenue and expenditure especially in agricultural production. So, the average of data about household heads at most and at least estimation were collected to overcome these challenge.

\subsection{Method of Data Analysis}

Data analysis started with summarization of socio economic variables. Preparing average annual UA net revenue per capita and other added up predictors in a suitable form using excel sheet were the first work. For the dependent variables excel sheet was also used to make it in binary form. Because of resource limitation only food security was analyzed using model. Other the rest four livelihood security categories (i.e education, health, empowerment and economic security alnyisis using correlation studies in descriptive analysis part. The regression output were analyzed and presented in the table. Finally, graph used to show the probability of dependent variable in respect to change of target variable while other predictors keeping constant.

\subsection{Model Specification}

The model was specified as the following logit $\mathrm{FSA}_{\mathrm{i}}=\alpha+\beta_{1} \mathrm{H}_{\mathrm{i}}+\beta_{\mathrm{i}} \mathbf{X}_{\mathrm{i}}$

FSA can be food security binary level of agreement. $\mathrm{H}$ represents average annual urban agricultural net revenue per capita. This was the study target explanatory variable for household i. As stated befor it classified into five in such a way that relatively lowest, lowest, medium, highest, and very highest revenue with respective valuation of 1, 2, 3, 4 and 5 . These were because of logistic coefficient too small if it were taken in regression as it is. The other explanatory were $\mathrm{Xi} \mathrm{s}$ which affects the dependent variable directly or through target variable.

\subsection{Regression Technique}

The regression technique of the study was binary logistic regression; which is used to predict a binary dependent variable given one or more independent variables with various measurement types. This regression type helped to determine which of our independent variables have a statistically more significant effect on dependent variable $[30,14]$. For the reason of constraint mentioned above in the introduction section, the study used only one binary logistic regressions (for only food security agreement).

\section{Result}

This chapter has two parts of analysis. The first parts are descriptive analysis and the second is analysis using model. In the descriptive analysis part household livelihood category and indicators and participation in a particular livelihood choice were summarized. In the model analysis part, only one model constructed to examine urban agriculture contribution to food security status of households.

\subsection{Descriptive Analysis}

The study also proceeded to summarize the five livelihood security categories for the sampled households.

Table 1. Summarization of household livelihood security categories.

\begin{tabular}{llll}
\hline Variable & Obs & $\begin{array}{l}\text { For lower security } \\
\text { Agreement }\end{array}$ & $\begin{array}{l}\text { For more Security } \\
\text { agreement }\end{array}$ \\
\hline Economic security & 399 & $372(93.23)$ & $27(6.77)$ \\
Health security & 399 & $145(36.34)$ & $254(63.66)$ \\
Education security & 399 & $148(37.00)$ & $252(63.00)$ \\
Empowerment security & 399 & $180(45.11)$ & $119(54.89)$ \\
Food security & 399 & $130(32.58)$ & $269(67.42)$ \\
\hline
\end{tabular}

From the above table 4 the number of households with percent's in bracket for lower and more (higher) secured households in column three and four respectively. For example 372 urban agricultural households economically lower secured, which was about $93.23 \%$ of sampled households and the rest 27 urban agriculture households were relatively higher economic secured, which was about $6.77 \%$ of sampled household. From the above table the lower and more (higher) secured household decided after constructing compressive index and then assign value zero for lower secured if the comprehensive index less than or equal to 0.5 
and one for higher secured households if it was greater than 0.5. Household credit, household saving and household annual agricultural and non- non net revenue were analyzed in the following table 2 .

Table 2. Summarization of household economic security indicators.

\begin{tabular}{llllll}
\hline Variable & Obs & Mean & Std. Dev & Min & Max \\
\hline Credit level of HH & 399 & 2261.965 & 5051.941 & 0 & 50000 \\
Saving level of H & 399 & 20811.9 & 34680.6 & 0 & 250000 \\
AAUA net revenue & 399 & 46663.54 & 24413.98 & 3800 & 99040 \\
AANUA net revenue & 399 & 8290.351 & 15232.84 & 0 & 88000 \\
Total AA net revenue & 399 & 54953.89 & 27954.19 & 3800 & 186000 \\
\hline
\end{tabular}

The above table 2 summarizes the current credit, saving, total household annual average net revenue of UA and nonUA participant household. As showed above in table 2, the mean of credit, saving and total annual average net revenue of UA participants was about 2261.965, 20811.96 and 54953.89 Ethiopian birr respectively. Average annual UA contribute to the total household annual average net revenue with mean of 46663.54 Ethiopian birr.

As stated before, the study's used economic security indicators are credit $(0,50000)$, saving $(0,250000)$ and total annual verage household net revenue $(3800,186000)$ with minimum and maximum associated respective value in bracket in Ethiopia birr. The study also further summarized UA participant household's livelihood choice as showed in the following table 3 .
Table 3. Summarization of $H H$ participation in a particular livelihood choice.

\begin{tabular}{llll}
\hline \multirow{2}{*}{ livelihood choice } & \multirow{2}{*}{ Obs } & \multicolumn{2}{c}{ Number of household (percent) } \\
\cline { 3 - 4 } & & Code zero & code one \\
\hline Fruit \&vegetable G. & 399 & $148(37.09)$ & $251(62.91)$ \\
Grain and teef P. & 399 & $210(52.63)$ & $189(47.37)$ \\
Animal fattening & 399 & $330(82.71)$ & $69(17.29)$ \\
Fishing & 399 & $332(83.21)$ & $67(16.79)$ \\
Bee keeping & 399 & $395(99.00)$ & $4(1.000)$ \\
Cattle rearing & 399 & $237(59.40)$ & $162(40.60)$ \\
Sheep \&goats & 399 & $312(78.20)$ & $87(21.80)$ \\
Hen rearing & 399 & $131(32.83)$ & $268(67.17)$ \\
Other work & 399 & $361(90.48)$ & $38(9.52)$ \\
Non-UA work & 399 & $246(61.65)$ & $153(38.35)$ \\
\hline
\end{tabular}

Note: code zero for non-participated and code one for participated in specific livelihood activities (choice) listed above in the first and second column respectively. $\mathrm{P}$ and $\mathrm{G}$ represents production and growing.

As shown above table 3, households participated in hen rearing (or may for egg production) was the highest of all other agricultural livelihood choices. That was $268 \quad(67.17 \%)$ households participated in hen rearing and 131 (32.8\%) were non- participated. The second is households participated in fruit and vegetable growing (251 households), which were $62.91 \%$ and the rest of $148(37.09 \%)$ households were non-participated. The $3^{\text {rd }}, 4^{\text {th }}, 5^{\text {th }}, 6^{\text {th }}, 7^{\text {th }} \& 8^{\text {th }}$ were agricultural households who participated in grain and teef production (189), cattle rearing (162), non-agricultural work (153), animal fattening (69), fishing (67), other UA work (38) and bee keeping (4) with number of households in bracket respectively.

Table 4. Correlation of livelihood security's with agricultural and non-sourced revenue.

\begin{tabular}{lll}
\hline Livelihood security agreement & $\begin{array}{l}\text { Average annual urban agricultural net revenue per } \\
\text { capita (H) }\end{array}$ & $\begin{array}{l}\text { Average annual non- urban agricultural net } \\
\text { revenue per capita (K) }\end{array}$ \\
\hline Economic & 0.6762 & 0.3300 \\
Food & 0.2953 & -0.0132 \\
Empowerment & 0.2269 & -0.0293 \\
Education & 0.1954 & -0.0939 \\
Health & 0.2159 & -0.2020 \\
\hline
\end{tabular}

The above table 4 shows that the correlation of livelihood security's with average annual urban agricultural net revenue per capita $(\mathrm{H})$ and average annual non- urban agricultural net revenue per capita $(\mathrm{K})$. As you showed above table all five livelihood security i.e economic, food, empowerment, education and health positively associated with average annual urban agricultural net revenue per capita. There correlations were about $0.6762,0.2953,0.2269,0.1954$ and 0.2159 respectively. But, average annual non- urban agricultural net revenue per capita $(\mathrm{k})$ were only positively associated with economic security. Other the rest livelihood security negatively associated with non- urban agricultural sourced revenue.

\subsection{Analysis Using Model}

The best selected specified model using likelihood ratio test was the following:

$\operatorname{logitFSA} A_{i=} \alpha+\beta_{1} \mathrm{H}_{\mathrm{i}}+\beta_{2} \mathrm{~K}_{\mathrm{i}}+\beta_{3} \mathrm{RLSPC}_{\mathrm{i}}+\beta_{4} \mathrm{FLSPC}_{\mathrm{i}}+\beta_{5} \mathrm{DR}_{\mathrm{i}}+\beta_{6} \mathrm{AE}_{\mathrm{i}}$

$$
+\beta_{6} \mathrm{LOCDUM}+\mathrm{e}_{\mathrm{i}}
$$

The regression output for the above best fitted model were showed in the following below table 5. Were FSA is food security agreement (it takes 1 for more agreed, otherwise zero), i represent individual household, ei is deviance residuals.

Table 5. Logit coefficient, odd ratio and marginal effect of regression output.

\begin{tabular}{llll}
\hline \multirow{2}{*}{ VARIABLES } & \multicolumn{2}{l}{ Food security agreement level } \\
\cline { 2 - 4 } & Logit coefficient & Odd ratio & Mfx \\
\hline $\mathrm{H}$ & $0.564 * * *$ & $1.758^{* * *}$ & $0.098^{* * *}$ \\
$\mathrm{~K}$ & $(0.146)$ & $(0.25)$ & $(0.024)$ \\
& 0.0981 & 1.103 & 0.017 \\
RLSPC & $(0.252)$ & $(0.277)$ & $(0.043)$ \\
& $0.0117^{* * *}$ & $1.011^{* * *}$ & $0.002 * * *$ \\
FLSPC & $(0.002)$ & $(0.002)$ & $(0.000)$ \\
& $1.935^{* * *}$ & $6.924 * * *$ & $0.337 * * *$ \\
DR & $(0.694)$ & $(4.803)$ & $(0.117)$ \\
& $-0.804 * * *$ & $0.447 * * *$ & $-0.140^{* * *}$ \\
AVE & $(0.263)$ & $(0.117)$ & $(0.047)$ \\
& $0.149 * * *$ & $0.447 * * *$ & $0.025 * * *$ \\
LOCDUM & $(0.0519)$ & $(0.117)$ & $(0.008)$ \\
\multirow{2}{*}{ Constant } & $-0.411 * *$ & $1.160^{* *}$ & $-0.065^{* *}$ \\
\hline
\end{tabular}




\begin{tabular}{llll}
\hline \multirow{2}{*}{ VARIABLES } & \multicolumn{4}{l}{ Food security agreement level } & \\
\cline { 2 - 4 } & Logit coefficient & Odd ratio & Mfx \\
\hline \multirow{2}{*}{ Observations } & $(0.772)$ & $(0.150)$ & \\
\hline
\end{tabular}

Note: Standard errors in parentheses ${ }^{* * *} \mathrm{p}<0.01,{ }^{* *} \mathrm{p}<0.05,{ }^{*} \mathrm{p}<0.1$

\subsection{Interpretation of Regression Output}

Other things remain the same for all interpretation of the following. The interpretation of logit coefficient for one birr increment of annual average UA net revenue per capita were not correct. A one birr change has negligible effect on logit coefficient of more food security agreement. So, annual average UA net revenue per capita classified into five with another evaluation from 1 up to five for every 6550 birr up to the maximum revenue of 32667 birr. So, from above table 5; for 6550 birr increment of annual average UA net revenue per capita results increment of more agreed food security households by 0.564 logit coefficient and this explanatory variable were positive significant at one percent. The change of probability from low agreed to more agreed household's $(\mathrm{mfx})$ when urban average UA net revenue per capita increased by 6550 birr were 0.098 . Annual averages UA net agriculture highly useful for the livelihood of urban households. Annual average non UA net revenue per capita positive insignificant at $5 \%$ and above. It has lower logit coefficient and marginal probability than agricultural sourced net revenue per capita as you look in the above table 5. The share of farmland size and residential land size of a family member positively associated logit coefficient of more agreed food security. The one hectare individual share of farm land size in a family member associated with 1.935 logit coefficient of more agreed food security agreement. The same thing the logit coefficient of more agreed food security associated the one meter individual share of residential land were about 0.011 . This show the size of farm land has greater contribution for the practice of urban agriculture than the residential land size area in turn it has greater contribution to food security. Hence it has greater logit coefficient. Another positive significant variable were average education level. The one year greater of average education level results 0.149 logit coefficients of more agreed food security through the work of agriculture in the cities. The ratio of non- working to working number of individual and location dummy were a negative significant variable for food security agreement. That means 0.1 increment of dependency ratio associated with decrement of logit coefficient by 0.804 . Working peoples were a greater contribution to agricultural work in the cities and towns. Location dummy were insignificant variable at $10 \%$ significance level as you look above table 5 . Eventhough it were insignificant variable at $10 \%$, household living in the pre- urban area were negatively associated with 0.411 logit coefficient. That means households who practiced urban agriculture in the cities has a greater food security agreement than households who practiced agriculture in the prie-urban.

The following graph helps to understood how about the probability of food secured agreement level in response to increasing of average annual UA net revenue per capita.

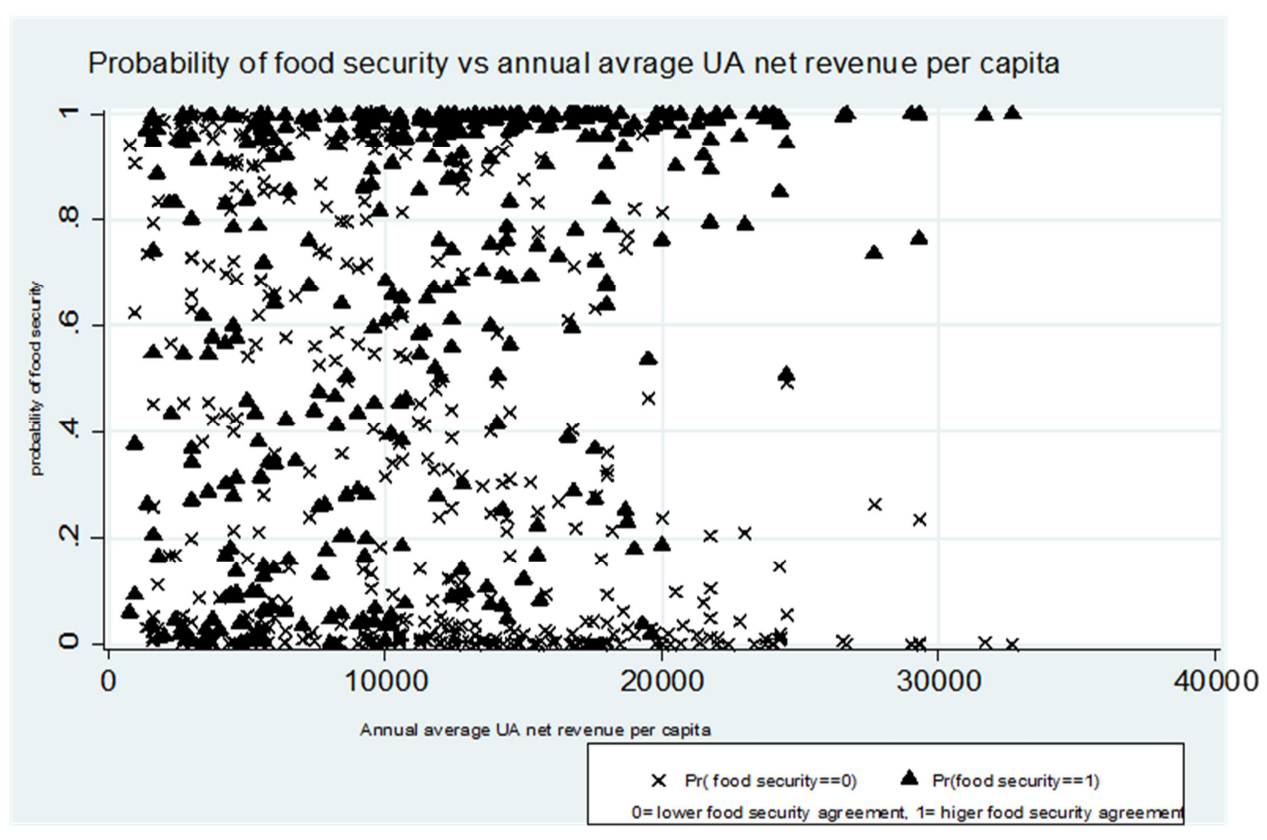

Figure 1. Probability of food security agreement level vs. UA revenue.

From the above graph one can refer the pattern of probability of food security agreement level with average annual UA net revenue per capita. The triangle $(\Delta)$ represents the probability of more agreed household's. The cross sine (X) also symbol represents the probability of lower agreed households on their food security status against average annual UA net revenue per capital. Relatively the probability of lower agreement of food security was very high at a lower average annual UA net revenue per capita. But, with increment of average annual UA net revenue per capita, the 
probability come to down to the lower level. Mostly for more agreed households the opposite is true.

\section{Discussion}

Generally households lived apart from the center of the cities were the more agricultural practitioners and households lived nearer to the cities center were the lower agricultural practitioners and the more participation in other livelihood choice. In another expression households were lived in the prei-urban area were more agricultural participants and households were lived in the urban area were the lower agricultural participants. The positive strong correlation of livelihood security with average annual urban agricultural net revenue per capita $(\mathrm{H})$ shows urban agriculture is essential and it can be major livelihood activity for urban poor.

Both logit coefficient and odd ratio was positive and pvalue of target variable was less than 0.01 . So, we can conclude that urban agricultural revenue statistically positive significant effect on agreement level of food security and. At the mean value of all predictors, the probability of more agreed households on their food security was about was about 0.77 . Therefore, the study's seeks to [21, 23, 24] conclusions; urban agriculture has a great contribution to food security and it can be major livelihood activities.

\section{Conclusion and Recommendation}

\subsection{Conclusion}

Generally, urban agriculture plays a vital role for household who choice as a means of fulfilling their livelihood outcome. The contribution of average annual UA net revenue per capita in response to a change of more agreed food security categories of [17] in reference to lower agreed food security categories was statistically positive significant at $1 \%$. On average 6550 birr increment of annual average UA net revenue per capita results increment of more agreed food security households by 0.564 logit coefficient, citrus paribus assumption. The correlation between economic, food, empowerment, education and health with average annual urban agricultural net revenue per capita were about 0.6762 , $0.29,0.22,0.195$ and 0.215 respectively. But, average annual non- urban agricultural net revenue per capita were only positively associated with economic security; which were 0.33 . From this result one can conclude the contribution of urban agriculture to household's food security status was great and it has also very high contribution for education security status of households in the cities. Its revenue enabled to educate their child's in the school and also its work serves as to collect natural knowledge. Participating in production of different notorious and healthy food type has great positive contribution to household health security status and its activity was important for household family member's to be physically strong and mentally active. It has also positive contribution to empowerment status of households. Because, decision making of family members and female participation in the agricultural activities altogether positively correlated with average annual UA net revenue per capita. Urban agricultural revenue highly correlated with economic security as well; its contribution was till so great. That was most of households that were relatively higher economically status positively associated with higher average annual UA net revenue per capita.

\subsection{Recommendation}

1) Institution should be established to promote, enhance and develop UA.

2) Urban agriculture should be considered in urban planning.

3) Frequent and continuous training, technical advice and material support should be provided by the government to urban agricultural participants to enhance the productivity and economic viability of urban agriculture.

4) Stakeholders should encourage urban agricultural household by providing loans, credit facilities with lowinterest rates, subsidize inputs for urban agricultural participants

5) Urban waste should be treated and for use of urban agricultural participants.

Areas of further studies:

1) Research on the challenge of agriculture for further advancement in the urban area.

2) Research on the effect of animal fatting to the livelihood of household in the urban.

3) Research on the effect of urbanization to the farm household livelihoods the urban.

4) Research on the effect of farmland selling to the livelihood of farmers in the urban.

\section{Abbreviation and Acronym}

$\begin{array}{ll}\text { BCUAL\&EPA } & \begin{array}{l}\text { Urban Agriculture, Land and Environmental } \\ \text { office Protection Authority }\end{array} \\ \text { BDC } & \text { Bahir Dar City } \\ \text { CSA } & \text { Central Statistical Authority in Ethiopia } \\ \text { DFID } & \text { Department for International Development } \\ \text { DF } & \text { Degree of freedom } \\ \text { FAO } & \text { Food and Agricultural Organization } \\ \text { FGT } & \text { Foster Greer Thornback } \\ \text { GFPR } & \text { Global Food Policy Report } \\ \text { GLOPP } & \text { Globalization and Livelihood Options of } \\ \text { HH } & \text { poverty } \\ \text { LR } & \text { Household } \\ \text { Mfx } & \text { likelihood ratio ch }{ }^{2} \text { statistic } \\ \text { UA } & \text { Marginal effect } \\ \text { UN } & \text { Urban Agriculture } \\ \text { UNDP } & \text { United Nation } \\ \text { US } & \text { United Nation Development Program } \\ \text { WB } & \text { World Bank }\end{array}$




\section{References}

[1] Alberto Zezza and Luca Tasciotti. (2008). Does urban agriculture enhance dietary diversity? Empirical evidence from a sample of developing countries.

[2] Bergman, U. M. (2004). Urban and peri-urban agriculture for food security in low- income countries. Kenyatta University. Nairobi.

[3] BCUAL\&EPA. (2009). Bahir Dar city urban agriculture, land and environmental protection. Budget report, Bahir Dar, Ethiopia.

[4] CSA (2016). National population statistical agency: Addis Abeba, Ethiopia.

[5] Duressa, T. F. (2007). Livelihood dependence on urban agriculture. Thesis report of partial fulfilment for Master of degree, Addis Abeba, Ethiopia.

[6] FAO. (2007). Presentation for the world urban problem solutions. Profitability and sustainability of urban and periurban agriculture.

[7] FAO. (2008). Presentation report about urban agriculture for sustainable poverty alleviation and food security in conference of world meeting in Rome.

[8] FAO. (2013). New approaches to the measurement of food security: hunger scale. Statistics division.

[9] Frankenberger \& Maxwell, D. (2000). Operationalizing household livelihood security.

[10] Gaféias (2017). Urban problems: Street children in Bahir Dar city. NGO Corporation document Power point. Ethiopia.

[11] Githugunyi, D. K. (2014). An assessment of the contribution of urban agriculture to households Livelihoods. Kenyatta University, environmental planning and Management in the school of environmental studies. Roysambu-ward, Nairobi.

[12] Golnaz R. and Z. Mohamed. (2016). Urban agriculture: a way forward to food and nutrition security in Malaysia. Urban planning and architecture design for sustainable development, $39-4$.

[13] Goraw Goshu and Shimelis Aynalem. (2017). Social and ecological system of dynamices characterstices, trends and integration in the Lake Tana in Ethiopia. Swizerland: springer international.

[14] Gujarati (2004). Basic econometrics (4 edition). Chapter 610. The megraw-hill companies.
[15] Jac Smit, Joe Nasr and Annul Ratta. (2001). Benefits of urban agriculture. In urban agriculture food, jobs and sustainable cities (4 ed.). UNDP.

[16] Kothari, C. (1990). Book of Reaserch methodology (2 ed.). New Delhi: new age International.

[17] Lindenberg, M. (2002). Measuring household livelihood security at the family and community level in the developing world. 30 (2), 301-318.

[18] Lohnert, B. (2017). Migration and the rural-urban transition in sub-Saharan Africa. Centre for rural development.

[19] Mireri (2013). Assessment of the contribution of urban agriculture to employment, income and food security. African journal of agricultural.

[20] Morse, M. and Mcnamra, N. (2013). The theory behind the sustainable livelihood: The integration of urban agriculture and the socio-economic lands cape.

[21] Ogunniyi, Fanifosi Komolafe (2017). The contribution of urban agriculture to household food insecurity. Scientia agriculture, 17 (2).

[22] Nugent (2001). The impact of urban agriculture on the household and local economies.

[23] Remi Adeyemo, Sunday Ogunleye, Damilola Kehind and Anuoluwapo Ayodele. (2017). Urban agriculture and its effects on poverty alleviation: a case study of vegetable farming. Environment and sustainability.

[24] Shaheen Akter and Sanzidur Rahman. (2012). Investigating livelihood security in poor settlements. $86^{\text {th }}$ annual conference of the agricultural economics society (pp. 4-7).

[25] Sheila, G. (2013). Urban agricalture impacts: social, health and economic a litrature review. Univerity of Calfornia. Davis: sustinable agricalture reasech institute and enducation program.

[26] Sheilah Meikle, Tamsin Ramasut \& Julian Walker (2011).

[27] TANGO International, I. (2004). Measuring livelihood impacts: a review of livelihoods indicators. Care Bangladesh.

[28] Gebre, B. (2015). Assessing the contribution of urban agriculture to urban households.

[29] Boloso bombe town, Wolaita Zone, SNNPR, Ethiopia: Haramaya University. Van De Walle, D., \& Cratty, D. (2004). Is the emerging non-farm market economy the route out of poverty? Economics of transition, 12 (2), 237-274.

[30] Verbeek, M. (2004). A guide to modern econometrics. Southern Gate, Chichester, W., England: John wiley \& Sons LTD. 